\title{
PhotoClass: a new metrology for opto-electric performance of photovoltaic modules
}

\author{
Jimmy, Dubard ${ }^{1, a}$, Thierry, Valin ${ }^{1}$ et Saïd, Bouhtiyya ${ }^{1}$ \\ ${ }^{l}$ LNE, 29 avenue Roger Hennequin 78194 TRAPPES CEDEX, FRANCE
}

\begin{abstract}
Résumé. Le projet européen PhotoClass a pour but de définir une nouvelle métrique pour l'évaluation de la performance des modules photovoltaïques (PV). Cette performance sera basée sur la production d'énergie annuelle en fonction des conditions d'ensoleillement du lieu géographique d'installation du champ PV et non plus sur la puissance crête. Cela implique une caractérisation des propriétés opto-électriques des dispositifs PV, des sources d'ensoleillement naturel et artificiel et des instruments associés. Dans ce projet le LNE travaille sur la linéarité et la dépendance en température de la réponse des dispositifs PV. Il évalue les performances d'un simulateur solaire incorporant des LED. Il caractérise un spectroradiomètre à matrice de détecteur couvrant le domaine spectral $350 \mathrm{~nm}-2000 \mathrm{~nm}$ utilisé pour mesurer l'éclairement solaire produit par les simulateurs à impulsion et développe une procédure d'étalonnage spécifique de ce type de spectroradiomètre pour cette application.
\end{abstract}

\section{Introduction}

Photovoltaic (PV) is one of the more promising renewable energy source for sustainable development and particularly to meet the European 20-20-20 energy and environment target. PV market has increased rapidly worldwide in the last decade (50 billion Euros in 2012) and was dominated until recently by Europe. This huge investment is strongly dependent on PV device performance and uncertainty in evaluating this parameter has a large financial impact. The European Horizon 2020 programme is expected to invest nearly 6 billion Euros in secure, clean and efficient energy, of which a significant proportion will be invested in PV research. Improved metrics (including more accurate predictions of energypayback time and energy-return factors) for evaluating and comparing PV technologies are crucial to ensure that both public and private investment in R\&D is efficiently targeted.

Performance of PV module in term of energy produced is a key parameter for customers and investors when it comes to make a choice of the technology to use for a particular PV project. However, today module performance is based on the peak power obtained from the I-V curve measured under standard test conditions (irradiance $1000 \mathrm{~W} / \mathrm{m}^{2}$, sun spectrum AM1.5, temperature of the module $25^{\circ} \mathrm{C}$ ) [1]. These conditions are different from reality particularly in Europe, Therefore an evaluation of the energy produced is not possible based on peak power measurement. There is a lack of information about the behaviour of a module of a particular technology with respect to the specific climate conditions of a given part of a country. It is then necessary to develop a metrology for the characterisation of PV devices on all the parameters that may impact the output power: irradiance level, sun spectral distribution, sun incidence angle, module temperature. Moreover new technologies need reference devices in order to improve measurement uncertainty through a more direct traceability route that relies today on crystalline silicon PV cells [2,3] with a different spectral responsivity.

The EMRP ENG55 Photoclass project "Towards an energy-based parameter for photovoltaic classification" led by PTB (German metrology institute) aims at, defining a new metric for PV module performance evaluation based on energy production, and improving measurement uncertainty.

In this paper we report on the structure of the overall project. We will focus on the work that is performed by LNE.

\section{The Photoclass project}

The Photoclass project is aimed at addressing the following scientific and technical objectives:

- Development of a metric (energy based) for PV efficiency and the associated uncertainty budget. This is based on standardised environmental data-sets for Europe and beyond. (WP1)

- Development of robust and improved characterisation methods with an accuracy sufficient for the parameters necessary for the new metric (e.g. spectrally resolved angular dependency of the responsivity, low light performance, and temperature dependency).

- Reduction of the measurement uncertainty for the measurement of absolute irradiance of the natural and simulated Sun irradiation, spectrally and angularly

\footnotetext{
a jimmy.dubard@lne.fr
} 
resolved. The upper limit of the measured wavelength will be extended from $1050 \mathrm{~nm}$ to $2000 \mathrm{~nm}$.

- Validation of the spectrally and angularly resolved measurements of solar devices by comparison with integral measurements.
- Development of new reference devices for an accurate SI traceable calibration process from the cell to the solar park.

The structure of the project is depicted on figure 1 .

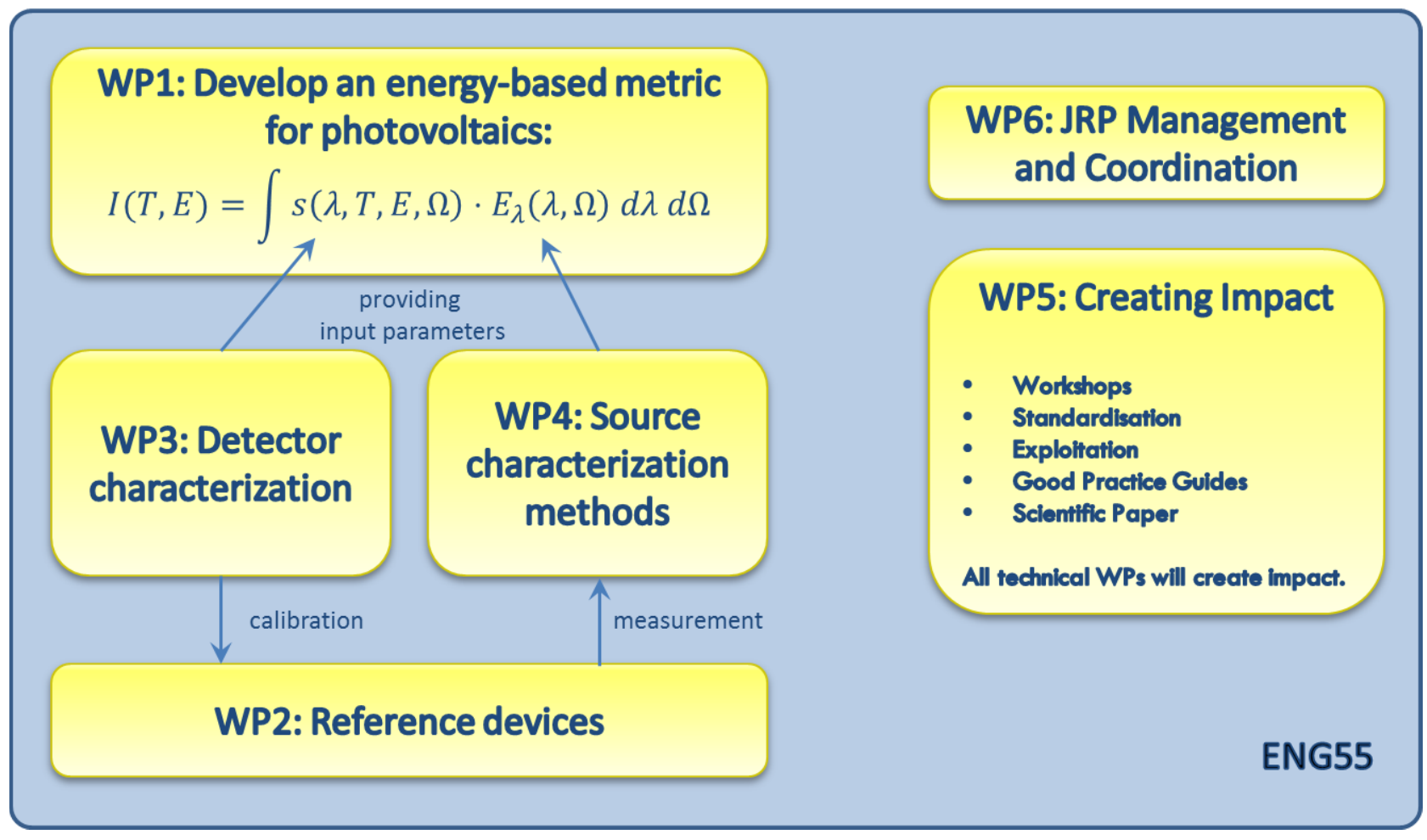

Figure 1: Structure of the Photoclass project (WP):

The project includes four technical workpackages

WP1 will develop and promote an energy classification scheme for PV. Software and tools will be developed for calculating the new metric and for estimating uncertainties and annual variations in energy yields as a function of location.

WP2 will concentrate on improving reference cells, including the reference cells for thin-film technology.

WP3 will develop methods to enable PV to be characterised more accurately and economically.

WP4 will concentrate on source (simulator) characterisation in order to reduce the uncertainty in PV performance measurements.

This three years project started in May 2014, involves nine partners including:

- Seven NMIs or DIs: PTB (D), INTA (E), JRC (European Commission), LNE (F), MIKES (Fi), NPL (UK), VSL (NL)

- $\quad$ Two laboratories: SUPSI (CH), TUV (D)

\section{LNE contribution}

LNE is involved mainly in two WP : WP3 and WP4. It is the leader of WP4.

\subsection{WP3: detector characterization}

The aim of this work package is to develop and improve detector characterisation methods for different types / technologies of solar cells. This WP includes 4 tasks :

- Task 3.1: New techniques for detector characterisation

- Task 3.2: Linearity characterisation of detector

- Task 3.3 : Temperature dependence of detector

- Task 3.4 : Angular dependence of the detector

LNE contribute to tasks 3.2 and 3.3

\subsubsection{Linearity characterisation}


The aim of this task is to investigate the impact of different irradiance levels on the PV devices manufactured with different technologies, designs and sizes.

LNE will use a sun flash simulator from CERTISOLIS with a $2 \times 2 \mathrm{~m}^{2}$ illumination area and a set of neutral density filters to evaluate the linearity of at least 6 mini-modules, 6 modules and 6 reference devices for different integral irradiance. The integral irradiance level will be monitored using a calibrated reference cell. The irradiance range from $100 \mathrm{~W} / \mathrm{m}^{2}$ to $1200 \mathrm{~W} / \mathrm{m}^{2}$ with a $100 \mathrm{~W} / \mathrm{m}^{2}$ step is achieved by selecting the proper filter and by adjusting the power of the Sun simulator.

\subsubsection{Temperature dependence}

The aim of this task is to determine the temperature coefficients of PV devices in relation to the technologies used, and their design and size. The major challenge is how to ensure and control a uniform thermal distribution in the solar device and this is difficult to achieve in standard laboratory environments. For extreme temperatures and large devices uniform thermal distribution can only be ensured in climate chambers since the solar cells will be in thermal equilibrium.

LNE is developing a climate chamber to allow the characterisation of mini-modules in the temperature range $0{ }^{\circ} \mathrm{C}$ to $65^{\circ} \mathrm{C}$. The design of this chamber is shown on figure 2. Heating or cooling is realized through the use of three thermoelectric coolers.

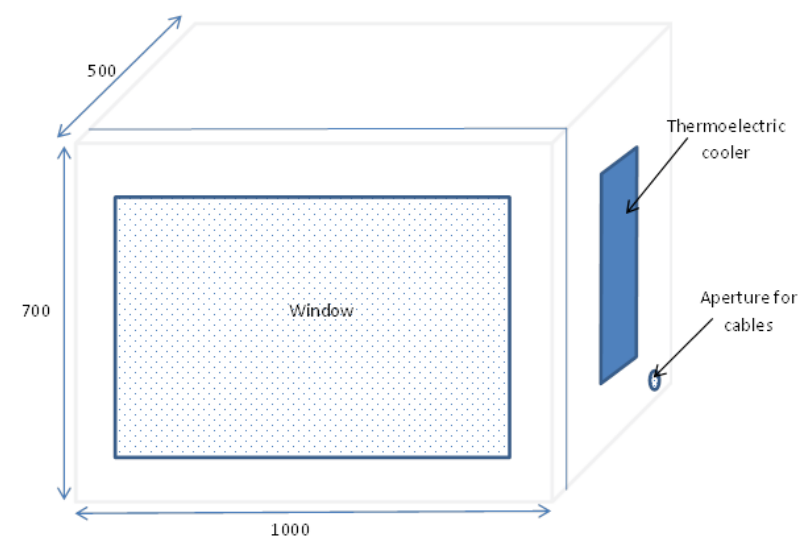

Figure 2. Design of the climatic chamber.

A flash sun simulator will be used to measure the I-V characteristics of the mini-modules. Spectral measurement at 5 selected wavelengths using interference filters will be performed to characterise the change in spectral response of each module with temperature.

\subsection{WP4: source characterization method}

The aims of this work package is to improve the traceability of the measurement of the spectral irradiance of the sources used to evaluate PV module performance, and to extend the actual upper limit spectral range capabilities of the array spectroradiometers that are used to characterise these sources from $1100 \mathrm{~nm}$ up to 2000 nm.

This WP includes 5 tasks :

- Task 4.1: Characterisation of the solar spectrum

- Task 4.2: Characterisation of pulsed solar simulators

- Task 4.3: Characterisation of a LED based solar simulator

- Task 4.4: Development of a simultaneous uniformimeter based on photodiode array

- Task 4.5: Uncertainty of spectrum measurements using spectroradiometers with different accuracy performance

LNE contributes to tasks 4.2 and 4.3

\subsubsection{Spectral characterisation of pulsed solar simulator}

The aim of this task is to determine the traceability of the measurement of the spectral irradiance of pulsed solar simulators with pulse duration of few $10 \mathrm{~ms}$.

To measure the spectral irradiance of pulsed solar simulators array spectroradiometers are the best candidate, because rotating grating spectroradiometers are not capable of acquiring the entire spectrum during the short pulse duration.

The work to be performed is:

- Characterisation of a UV-VIS-IR array spectroradiometer operating in the $300 \mathrm{~nm}-2000 \mathrm{~nm}$ spectral range which has been designed for pulsed solar simulator measurement. We will pay attention to linearity and stray light characterisation.

- Development of a calibration procedure taking into account the pulse mode operation of the sources to be measured.

- Evaluation of the uncertainty of the pulsed solar simulator spectral irradiance measurement using Monte Carlo (MC) techniques. We will benefit from our experience in $\mathrm{MC}$ uncertainty evaluation using of array spectroradiometers in the UV range[4, 5].

\subsubsection{Characterisation of a LED based solar simulator}

The aim of this task is to evaluate a new type of solar simulator that uses a set of LEDs (Light Emitting Diodes) to generate different AMx sun spectra. This would be an interesting tool for indoor PV module performance evaluation in the framework of the proposed new metric. Indeed to evaluate energy production it is necessary to measure the performance of the PV module under different source spectral distributions corresponding to the different sun elevations. Example of LED sun simulator spectrum in comparison of natural solar spectrum is depicted on figure 3 (from Wavelabs web site www.wavelabs.de) 


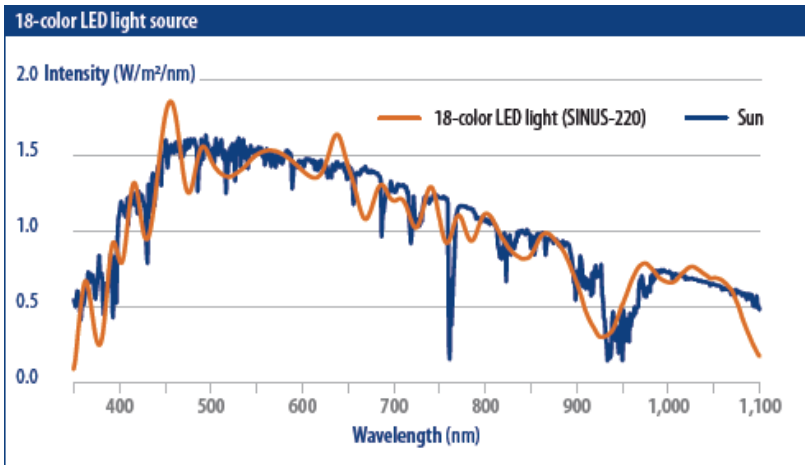

Figure 3: LED sun simulator spectral irradiance

The work to be performed is:

- Characterise the LED sun simulator in CW and pulse modes : spectral emission, temporal stability, spatial uniformity

- Measure PV module performance using LED sun simulator by comparison to classical indoor and outdoor measurements

- Evaluate the impact of this technology on spectral mismatch factor and uncertainty.

\section{Conclusion}

The aim of the PhotoClass project is to propose a new metric for photovoltaic (PV) module performance evaluation. This new metric is based on yearly energy production instead of peak power.

Beyond state of the art techniques have to be developed to characterise the properties of PV devices, sun simulator and related instrumentations.

LNE will work on linearity and temperature dependence of PV devices using a sun flash simulator. New LED based sun simulator will be investigated. UV to IR (up to $2000 \mathrm{~nm}$ ) array spectroradiometre will be characterised and a dedicated calibration procedure will be implemented.

\section{References}

1. IEC 60904-1, Photovoltaic devices - Part 1: Measurement of photovoltaic current-voltage characteristics, September 2006

2. C.R. Osterval et al., Prog. Photovolt. 7, 4, (1999)

3. J. Dubard, J.R. Filtz, V. Cassagne, P. Legrain, Measurement, 51, (May 2014)

4. A.F. Obaton, J. Lebenberg, N. Fisher, S. Guimier, J. Dubard, Metrologia, 44, (2007)

5. J. Dubard, R. Etienne, T. Valin, CIE Expert Symposium on Measurement Uncertainties in Photometry and Radiometry for Industry, Vienna, Austria, (September 2014) 